\title{
Dinosaur trackways from the early Late Cretaceous of western Cameroon
}

Jeremy E. Martin ${ }^{1}$, Elie Fosso Menkem ${ }^{2,4}$, Adrien Djomeni ${ }^{3}$, Paul Gustave Fowe ${ }^{3}$ and Marie-Joseph Ntamak-Nida ${ }^{3}$

${ }^{1}$ Université Lyon 1, ENS-Lyon, CNRS, UMR 5276 LGL-TPE, F-69622, Villeurbanne, France. jeremy.martin@ens-lyon.fr

${ }^{2}$ Université de Yaoundé I, Faculté des Sciences, Département des Sciences de la Terre, BP 812 Yaoundé, Cameroun

${ }^{3}$ Université de Douala, Faculté des Sciences, Département des Sciences de la Terre, BP 24157 Douala, Cameroon.

${ }^{4}$ Université de Rouen, Département de Géologie-UMR-CNRS 6143, 76821 Mont Saint Aignan CedexFrance.

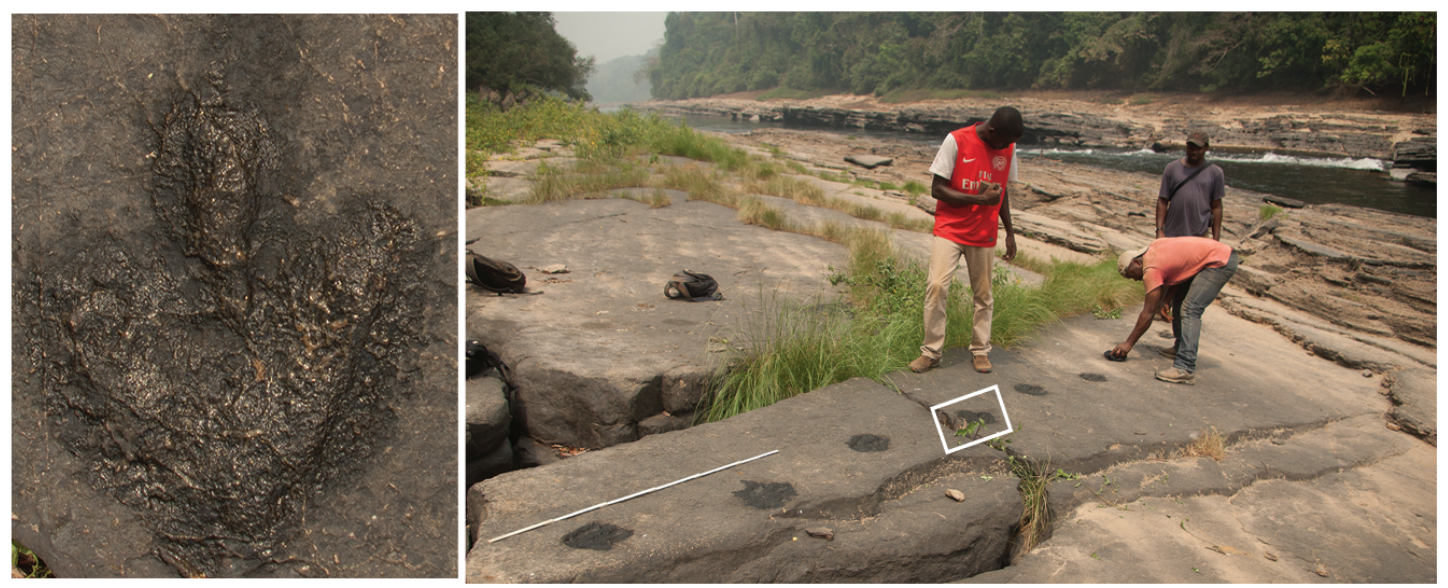

Abstract. Dinosaur trackways have rarely been reported in Cretaceous strata across the African continent. To the exception of ichnological occurrences in Morocco, Tunisia, Niger and Cameroon, our knowledge on the composition of Cretaceous dinosaur faunas mostly relies on skeletal evidence. For the first time, we document several dinosaur trackways from the Cretaceous of the Mamfe Basin in western Cameroon. Small and medium-size tridactyl footprints as well as numerous large circular footprints are present on a single horizon showing mudcracks and ripple marks. The age of the locality is considered Cenomanian-Turonian and if confirmed, this ichnological assemblage could be younger than the dinosaur footprints reported from northern Cameroon, and coeval with or younger than skeletal remains reported from the Saharan region. These trackways were left in an adjacent subsiding basin along the southern shore of the Benoue trough during a time of high-sea stand when the Trans-Saharan Seaway was already disconnecting West Africa from the rest of the 
continent. We predict that other similar track sites may be occurring along the margin of the Benoue trough and may eventually permit to test hypotheses related to provincialism among African dinosaur faunas.

Keywords: dinosaur footprints, Cretaceous, Benoue trough, paleobiogeography

\section{Introduction}

Dinosaur trackways are rarely reported from the Cretaceous of Africa. The youngest occurrence consists of a single mention from the Maastrichtian of Morocco (Ambroggi and Lapparent, 1954). To this exception, all other reports are from the Lower Cretaceous of Morocco, Niger and Cameroon. Recent reports for Morocco consist of Barremian-Aptian dinosaur footprints that include two quadrupedal trackways assigned to the ichnogenus Brontopodus (Masrour et al. 2013). Cretaceous theropod footprints were found on isolated slabs from the Kem Kem beds of Morocco (Belvedere et al., 2013). As for the rest of North Africa, around 300 footprints including tridactyl and circular footprints were reported from the Albian-Cenomanian of Niger (Ginsburg et al. 1966). No trackways were formerly described from Niger but the abundance of footprints mentioned by Ginsburg et al. (1966) invites for further exploration. Dinosaur footprints represented by theropod and sauropod footprints are also known from the Valanginian of Amoura, Algeria (Bellair and Lapparent, 1948; Bessedik et al. 2008). Ornithopod and theropod trackways were reported from the Albian of Tunisia (Contessi, 2013a ; Contessi and Fanti, 2012b). Small tetrapod footprints were also reported from the Cretaceous of Egypt and Sudan (Demathieu and Wycisk, 1990).

All remaining evidence for dinosaur trackways is to be found in Central Africa and more specifically in northern Cameroon. The existence of dinosaur footprints in Early Cretaceous deposits of northern Cameroon was revealed thanks to fieldwork conducted more than 30 years ago (Flynn et al., 1987; Jacobs et al., 1989; Dejax et al., 1989; Congleton, 1990). These discoveries were part of a broader field investigation that led to the identification of several fossiliferous localities (Congleton, 1990; Flynn et al., 1987). Theropod, ornithopod and sauropod footprints are known from the ?Barremian of the Babouri-Figuil Basin of Cameroon (Dejax et al. 1989) and theropod and sauropod footprints were reported from the ?Aptian-Albian of the Koum 
Basin, Cameroon (Congleton, 1990). Congleton et al. (1990) use the fauna of Mayo Djarendi to propose a correlation between continental sediments of the Koum basin with those of the Gadoufaoua localities in Niger on the basis of the shared presence of Aff. Araripesuchus, cf. Spinosauridae and Ouranosaurus sp.. The fossiliferous sites in Gadoufaoua are considered Aptian-Albian in age (Taquet, 1976). Dinosaur footprints of the Koum Basin were all recovered from the Mbissirri Member and include theropod, ornithopod and sauropod footprints (Congleton, 1990) and occur below the horizon that previously produced teeth and bones mentioned in the literature (EFM, pers. obs. 2010). Thus, our knowledge of Cretaceous continental vertebrate assemblages in Cameroon is restricted to the Lower Cretaceous.

Extensive sedimentary sequences rarely crop out in densely forested areas preventing a detailed knowledge of the fossil record from today's equatorial and tropical environments. Our recent exploration of sediments in the Mamfe Basin of Western Cameroon in February 2016 led to the discovery of several dinosaur trackways along the Manyu River (Fig. 1). According to Martin Abolo (pers. comm. 07/2016), dinosaur footprints from the Mamfe Basin have been briefly mentioned in a confidential report from the IRGM/SNH (Institut de Recherche Géologique et Minière/Société Nationale des Hydrocarbures). However, we have been unable to locate the document.

The dinosaur trackways described here are saurischian-dominated and could be younger than the vertebrate fauna from Babouri-Figuil (Barremian according to Brunet et al. (1988)) and younger than the trackways from the Koum Basin (AptianAlbian according to Congleton et al., 1990). Potentially, the Mamfe trackway assemblage could be coeval with or younger than deposits in North Africa that produced dinosaur skeletal remains. In the present report, we preliminary document the diversity of trackways recovered during our mission and discuss the composition, paleoecology and paleobiogeographic context of the discovery.

\section{Geological setting}

The Benue Trough and associated basins (Fig. 1a) including the Gongola Trough (extending N-S mostly in Nigeria), Bornu (extending W-E and reaching Cameroon eastwards) and Yola basins are located in the convergence of the West African Rift System (WARS) and Central African Rift System (CARS) in the junction between the Northwest, Northeast and Southern African plates (Benkhelil, 1989, Heine et al. 
2013). The Benue Trough represents the abandoned arm of a ridge-ridge-fault triple junction at the origin of the opening of the South Atlantic Basin and extension in the WARS and CARS (Popoff, 1988; Benkhelil, 1989; Fairhead and Okereke, 1990; Genik, 1993, 1992; Guiraud et al., 2005). The Trough represents a major direction of NE-SW filled with continental and marine sediments. Subsidence in the Benue Trough begins during the Late Jurassic - Barremian interval (Benkhelil, 1989; Guiraud and Maurin, 1992; Dejax and Brunet, 1996; Guiraud et al., 2005); the oldest sediments, Barremian in age (Brunet et al., 1988) are conglomerates, covered with lacustrine deposits. In northeastern Nigeria, marine conditions partly occurred during the latest Cenomanian-latest "Senonian", (Campanian-Maastrichtian?) interval (Vullo and Courville, 2014). Favorable conditions for trackway preservation might be related to transgression events during the expansion of the Trans-Saharan Seaway with the subsequent aggradation of siliciclastic sediments in structural basins close to the Benue Trough system.

The Mamfe basin is an appendix of the Benue Trough located at the South East border (Fig. 1b); the major direction is NW-SE from Nigeria to South West Cameroon. This basin is located between $5^{\circ} 36^{\prime}-5^{\circ} 59^{\prime}$ of latitude $\mathrm{N}$, and $8^{\circ} 50^{\prime}-9^{\circ} 35^{\prime}$ of Longitude E. Mamfe basin is laterally correlated to the Asu River formation in Nigeria (Benkhelil, 1989). The study area corresponds to the Nfaitok Formation as described by Eyong (2003) and Eyong et al. (2013). This formation has been subdivided into three members namely Manyu, Mamfe and Bagba (Eyong, 2003).

All trackways described in this report were recovered from a single bed surface at the base of the Manyu member (Fig. 1c) that could be followed for more than 500 meters along the left bank of the Manyu River, downstream Nfaitok Bridge. The entire section is composed of thin alternations of claystones and siltstones grading to fine sandstones beds. Sedimentary structures on the surface of the bed are changing laterally with ripple marks and mud cracks. Footprints are concentrated in areas where mud cracks occur. The sedimentary sequence of the Mamfe Basin has been presented as Albian-Cenomanian in age (Dumort, 1968; see also summary in Eyong et al. 2013); a recent study proposes a Late Cenomanian-Turonian age for the sediments at Nfaitok Bridge on the basis of a palynomorph assemblage (Njoh et al. 2015).

\section{Material and methods}


Footprints have variably suffered from erosion. Therefore, in order to enhance their contrast, the sediment was cleaned with water, and footprints were photographed shortly after. A succession of pictures were shot at fixed height then reassembled in Photoshop to build a panorama. The best-preserved footprints were measured in the field (Table 1). Measurements are summarized in Table 1 and GPS positions are recorded in the collections of Equipe Bassins Sédimentaires du Laboratoire de Géosciences, Ressources Naturelles et Environnement, University of Douala. Preservation is not always fine and so only the best representatives of the trackways have been selected for individual footprint measurements (see Fig. 2 A'-C' and Table 1). Trackways have been identified with a field number with the acronym NFTK for Nfaitok locality.

\section{Description of the trackways}

Our survey of the Manyu riverbank near Nfaitok Bridge during the dry season in February 2016 led to the discovery of several dinosaur trackways. The particularly low level of the river allowed a preliminary exploration of the sandstone surfaces, otherwise underwater. Some areas were variably covered with less than $1 \mathrm{~cm}$ of dry mud deposited during the last seasonal flood and obscuring the bed surface. For this reason, discoveries of more footprints can be expected in the future, pending bed surfaces are explored during the dry season. The running water of the Manyu River abrades the surface of the sandstone layers and in many cases, footprints are eroded and difficult to discern. Two types of footprints were observed and are described here. The footprints are considered true tracks (sensu Lockley, 1991) as they are directly superimposed on mudcracks and ripple marks.

\subsection{Tridactyl footprints}

Five distinct trackways composed of medium-size (i.e. about $21-25 \mathrm{~cm}$ long) nearly aligned (low pes print rotation angle) mesaxonic footprints are distributed on a surface area of about $400 \mathrm{~m}^{2}$ (Fig. 2). The best-preserved trackways are described here but all identified trackways are listed in Table 1. The morphology of all footprints is similar with digit III being always longer than digits II and IV. Three trackways have interdigital divarication angles around $50^{\circ}$ (NFTK001, 002 and 004) and two of them 
around $40^{\circ}$ (NFTK003 and NFTK005). The best-preserved footprint belongs to trackway NFTK003 (Fig. 2C, 2C'). Here, traces of phalanges are well individualized in the print and at the level of the claw of the median finger. A nicely preserved trackway (NFTK001; Fig. 2A) is heading North to the river. This trackway contains 13 footprints, with an average footprint length of $21 \mathrm{~cm}$ and a pace length of $71.5 \mathrm{~cm}$. The longest trackway, about 25 meters long, includes more than 20 footprints, the majority of which are eroded and for this reason were not figured here (NFTK002; Table 1). The average footprint length measured here is $20 \mathrm{~cm}$ and the pace length is $110 \mathrm{~cm}$ (which diminishes to $100 \mathrm{~cm}$ near the most recent footprints). A trackway composed of 4 footprints (NFTK004) is heading West, with an average footprint length of $25 \mathrm{~cm}$ and a pace length of $117 \mathrm{~cm}$. Also in the same area, another trackway (NFTK005) is heading South-South-West and is composed of 6 footprints with an average footprint length of $20 \mathrm{~cm}$ and a pace length of $60 \mathrm{~cm}$. These footprints have all been partly eroded but remain visible. Located about 500 meters downstream, a suite of five relatively large footprints (NFTK006) is heading in a South-South-West direction. The average footprint length is $34 \mathrm{~cm}$ and digit III is also longer than all other digits. All footprints are nearly aligned (low pes rotation angle), have an interdigital divarication angle of $50.2^{\circ}$ and a pace length of $110 \mathrm{~cm}$.

\subsection{Circular footprints}

Circular footprints were discovered at four spots along the left bank of the Manyu River, two of which consist of partly eroded footprints on a limited area (Fig. 3C; Table 1). The two other spots were found close to the area of the medium-size tridactyl footprints, one upstream, another one downstream and consist of two distinctly recognizable trackways (Figs. 3, 4). All footprints are marked along their anterior margin by a bulge consisting of displaced sediment during pes/sediment contact. None of the sauropod tracks described here preserve claw marks. Pairs of pes-manus imprints are seldom visible (Fig. 3). Two types of trackways were observed: in trackway NFTK007, large circular to ovoid pes prints are accompanied by smaller circular manus prints; in trackway NFTK009, a single half-moon-shaped manus print accompanies several large circular footprints (Fig. 3C). The largest footprints measure more than $70 \mathrm{~cm}$ in diameter (NFTK009 and NFTK010; e.g. Fig. 3C). Further characteristics of the two best-preserved trackways are described below. 
The quadrupedal trackway NFTK007 (Table 1; Fig. 4) is the longest at this site consisting of 12 footprints with a slightly sinuous direction; however, there is a gap of preservation in the middle of the trackway with footprints having been completely eroded away for about 5 meters. In this trackway, the smaller circular imprints are interpreted as manus prints and they are always in line with pes prints and not located away from the trackway axis. However, the measured heteropody index is variable and is close to 2 at one end of the trackway (Fig. 4-northern end) and is close to 3.8 at the other end (Fig. 4-southern end), indicating variable competency of the sediment during the passage of the dinosaur. The trackway ratio established from pes measurements ranges from $35 \%$ to $40 \%$ along the trackway. This is indicating a medium to wide gauge for the trackmaker according to Romano et al. (2007).

Trackway NFTK009 preserves 8 footprints. Here, the heteropody index is high with the pes nearly twice as large as the manus (e.g. Fig. 3B). However, the trackway ratio appears different being about $50 \%$, which would fit in the lowest range of the narrow-gauge space presented in Romano et al. (2007).

\section{Discussion}

\subsection{Theropod diversity at Nfaitok Bridge}

The tridactyl nature of the footprints, the claw impression on the median digit, the low pes print rotation angle and the preservation of digital pads in some of the bestpreserved prints cannot be confounded with ornithischian trackways but are instead reminiscent of theropod trackways. Depending on their size, those theropod footprints may be assigned to the ichnogenera Grallator $(\mathrm{PL}<25 \mathrm{~cm})$ and Eubrontes $(30 \mathrm{~cm}<$ $\mathrm{PL}<50 \mathrm{~cm}$ ), both mainly reported from Late Triassic - Early Jurassic deposits (Olsen et al., 1998) but recently also reported from Cretaceous sediments in Africa (Bessedik et al., 2008; Contessi and Fanti, 2012b).

Following Alexander (1976), calculated heights at hip for theropod trackmakers vary between less than a meter and more than a meter and half for the largest individual (NFTK006), all indicating small to medium-bodied bipedal dinosaurs. Reconstructed speed (Thulborn, 1989) is independent of body size with some small individual recording varying slow to moderate speeds from 0.6 to $1.5 \mathrm{~m} . \mathrm{s}$ 
1. The largest individual (NFTK006) was walking with a speed of $1.1 \mathrm{~m} . \mathrm{s}^{-1}$. The recovery of at least six theropod footprints of slightly different footprint lengths on a relatively small surface area indicates that the place was visited by several individuals and their different directions of travel seem to indicate that these animals were not moving in group but instead were independent.

Comparing the track record with the osteological record is tentative because localities are distant and the age of continental deposits yielding dinosaur faunas is not always firmly established. As concerns small-bodied theropods from the Cretaceous of continental Africa, they are mostly known from isolated teeth, which indicate the presence of dromaeosaurids in Morocco, Sudan and Egypt (Rauhut, 1995; Amiot et al. 2004; Richter et al. 2013). Evans et al. (2014) described two small theropod femora from the Kem Kem beds of Morocco belonging to a noasaurid and to an indeterminate averostran theropod. The most complete small theropod individual is Nqwebasaurus thwazi, an ornithomimosaur from the Lower Cretaceous Kirkwood Formation of South Africa and would have had a hip height much smaller than a meter (De Klerk et al. 2000; Choiniere et al. 2012). The largest footprints observed at Nfaitok would correspond to medium-size animal (estimated hip height of $1.66 \mathrm{~m}$ ), comparable in size to the carcharodontosaurids Deltadromeus agilis from the Kem Kem beds of Morocco (Sereno et al. 1996) and Eocarcharia dinops from the AptianAlbian of Niger (Sereno and Brusatte, 2008) or to the abelisaurid Rugops primus from the Cenomanian of Niger (Sereno et al. 2004). Therefore, theropod diversity at Nfaitok Bridge could be represented by at least two taxa including a small size dromaeosaurid and a medium size theropod of uncertain affinities.

\subsection{Sauropod diversity at Nfaitok Bridge}

Large ( $>30 \mathrm{~cm}$ in diameter) circular footprints outlined by a bulge of displaced sediment and organized in a quadrupedal fashion are characteristic of sauropod dinosaurs. Here, sauropod trackways are short, poorly preserved and incomplete, rendering comparison with trackways from the literature difficult. Nevertheless, it should be emphasized that in the longest trackway (NFTK007), manus prints in line with pes prints as well as a medium to wide-gauge are features described for the ichnogenus Brontopodus from the Lower Cretaceous Glen Rose Limestone, USA (Farlow et al. 1992). Nevertheless, the variable heteropody index recorded here is 
puzzling because Brontopodus has been defined also on a moderate heteropody index (Farlow et al. 1992), therefore NFTK007 cannot be attributed to a given ichnotaxon with certainty. However, the wide-gauge trackway observed here may permit to infer that the trackmaker was a titanosaur. Wilson and Carrano (1999) suggest that titanosaurs produced wide-gauge trackways because of the morphology of their femur.

The attribution of the shorter trackway (NFTK009) to a given ichnotaxon is not conclusive. On the basis of its narrow gauge and high heteropody index it may be assigned to Parabrontopodus from the Morrisson Formation of Colorado (Lockley et al. 1994) but the pes prints are not longer than wide but nearly circular instead (Fig. 3). It therefore appears safe to recognize some similarities with both Brontopodus and Parabrontopodus but we refrain to firmly assign these sauropod footprints to a given ichnotaxon. As for the trackmaker, and although the present evidence cannot be considered to be definitive, rebbachisaurid sauropods have been hypothesized to leave narrow-gauge trackways. If valid, Mamfe trackway NFTK009 may indicate the presence of rebbachisaurids outside of their known range; until then known in northwestern African localities (Mannion and Barrett, 2013). Nevertheless, we stress again that the systematic value of trackway pattern (narrow versus wide-gauge) is debated and such a feature may not be diagnostic because sediment competency or other factors may affect the nature of both the heteropody index and of the gauge, questioning their validity for ichnotaxonomy (Farlow, 1992). Here, narrow- and medium to wide-gauge sauropod trackways are observed and it remains questionable whether a single or two different sauropod taxa left those trackways at Nfaitok Bridge.

The fossil record of African Cretaceous sauropods includes several taxa known from relatively complete or at least sufficiently diagnostic skeletal remains but mostly predating the Cenomanian marine transgression. The age of two titanosaurs from the lower Cretaceous Lupata Group of Malawi, Malawisaurus dixeyi and Karongasaurus gittelmani is not precisely known (Jacobs et al. 1993; Gomani, 2005) but post-Cenomanian sauropod remains are unknown from Central Africa. In the Saharan region of West Africa, two sauropods are known from the Aptian-Albian El Rhaz Formation of Niger: one unnamed titanosaur based on one astragalus and caudal vertebrae (Sereno et al. 1999) as well as the rebbachisaurid Nigersaurus taqueti described from relatively complete skeletons (Sereno et al., 1999; Sereno et al., 2007). 
This taxon is relatively small for a sauropod with a total length of about $9 \mathrm{~m}$ and about $2 \mathrm{~m}$ at hip height (Sereno et al., 2007). Further North in the early Albian Ain el Guettar Formation of Tunisia, another rebbachisaurid, Tataouinea hannibalis is known from caudal vertebrae and a sacrum and was estimated to be $14 \mathrm{~m}$ long (Fanti et al. 2013). Rebbachisaurids are restricted to West Africa whereas titanosauriforms are both found from West and Central Africa (see review in Mannion and Barrett, 2013). This hypothetic provincialism among Cretaceous sauropod faunas could be artificial and explained by poor sampling with most of the skeletal fossil record known from peri-saharan regions, where deposits are available. This is a particularly prominent problem because most of Central African regions are covered by dense vegetation. On the other hand, provincialism has been discussed under the light of the Trans-Saharan Seaway (Mannion and Barrett, 2013), isolating West Africa from the rest of the continent during the Cenomanian transgression (see discussion below). In any case, the described trackways do not permit to assess the presence of rebbachisaurids versus titanosaurs at Nfaitok Bridge but this question will have to be explored in further details if better-preserved trackways become available along the margin of the Benoue trough and its smaller sedimentary basins in Cameroon, Chad and Nigeria.

\subsection{Paleobiogeographical implications}

The presence of dinosaur footprints in the Mamfe Basin indicates a shallow deltaic or marginal setting and a close proximity of emerged land rather than a frank marine setting. A Cenomanian age has been proposed for Nfaitok Bridge sediments (Njoh et al. 2015) and the presence of microorganisms in the sedimentary sequence at Nfaitok Bridge indicates some marine influence (Njoh et al. 2015). The Benue trough is a tectonic basin that originates from the opening of the South Atlantic starting to be filled with the Trans-Saharan seaway during the Albian-Cenomanian-Turonian, eventually allowing a marine connection between the Atlantic Ocean and the Tethys (Philip et al. 1993a, b in Guiraud et al. 2005). Although hydrographic connections between the Mamfe Basin and the Benue trough are to be questioned, it is clear that terrestrial fauna living in the Mamfe Basin were isolated from the Western African landmass by the Trans-Saharan seaway, preventing biotic interchanges. 
A major paleogeographic change occurred during the Cenomanian as the sea invaded the northern African platform and then the Niger and Chad intra-continental basins, entering through narrow seaways both from the north (i.e. from the Neotethys) and from the south (i.e. from the South Atlantic via the Benue Trough) (Philip et al., 1993a, b in Guiraud et al., 2005; Vullo and Courville, 2014). The marine transgression culminated in the Late Cenomanian to Turonian times, associated with warm global climates and highest global Phanerozoic sea levels (Guiraud et al., 2005). Therefore, West Africa became isolated from the rest of Africa during the Cenomanian-Turonian interval before a regression took place during the Turonian, reconnecting the whole African continent (Guiraud and Maurin, 1992; Guiraud et al., 2005, Heine et al., 2013). The southern part of the Benue trough became inundated first as early as the Albian and it is later that the northern part of the Benue trough records marine deposits. Continental sedimentation begins earlier for the northernmost associated grabens of the Benue trough (Brunet et al., 1988) where dinosaur tracks are recorded as early as the Barremian in the Babouri-Figuil Basin (Dejax et al., 1989) and in the Aptian-Albian of the Koum Basin (Congleton, 1990). The Mamfe dinosaur fauna belongs to the same province as the other dinosaur faunas from northern Cameroon (i.e. the eastern margin of the Benue trough). Nevertheless, the dinosaur composition of northern sites in Cameroon could be different because of their older age (Barremian and Aptian-Albian) and because they record a window of time before the isolation of West Africa from the rest of the continent by the Cenomanian Trans-Saharan Seaway. A notable difference is the absence of ornithopod footprints in the Mamfe Basin, which are recorded in the Babouri-Figuil Basin (Dejax et al. 1989) and recorded in the Koum Basin with both footprints and teeth (Congleton, 1990). The sauropod trackways described here are are larger than those reported from Babouri-Figuil (Dejax et al. 1989) and equivalent in dimensions to those from Koum Basin (Congleton, 1990).

The present discovery predicts the occurrence of similar deposits containing dinosaur trackways along the shores of the Benue trough in Cameroon, Chad and Nigeria. Testing the timing of terrestrial faunal links between West and Central Africa in the context of the opening of the South Atlantic Ocean requires additional track sites and an improved temporal framework.

\subsection{Concluding remarks}


The discovery of dinosaur footprints in western Cameroon has important implications for paleobiogeography, biostratigraphy and paleontology: 1) they indicate that this area was emerged during the Cenomanian-Turonian, a time when the Trans-Saharan seaway was already in place; 2) those trackways may be younger than those from northern Cameroon; 3) they may be co-eval with or younger than most Cretaceous dinosaur discoveries in Africa; 4) they add to the limited record of dinosaur trackways in the Cretaceous of Africa and provide a glimpse into vertebrate community composition and ecology. Potential for future discoveries in the Mamfe basin remains high given the apparent extension of outcrops along the river, the continuous stratigraphic levels and the seasonally changing water level.

\section{Acknowledgements}

Fieldwork was supported by the National Geographic Society (grant NGS GEFNE 74-13). Martin Lockley, Richard T. McCrea and Michela Contessi provided constructive comments that helped improve the content of this work.

\section{References}

Alexander, R.M., 1976. Estimates of speed of dinosaurs. Nature 261, 129-130.

Ambroggi, R, Lapparent, A.F., de. 1954. Découverte d'empreintes de pas de Reptiles dans le Maestrichtien d'Agadir (Maroc). C. R. Somm. Soc. Géol. France 3, 5152.

Amiot, R., Buffetaut, E., Tong, H., Boudad, L., Kabiri, L., 2004. Isolated theropod teeth from the Cenomanian of Morocco and their palaeobiogeographical significance. Rev. Paléobiol. Vol. Sp. 9 , 143-149.

Bellair, P., Lapparent, A.F., De. 1948. Le Crétacé et les empreintes de dinosauriens d'Amoura (Algérie). Bull. Soc. Hist. Nat. Afr. Nord 39, 168-175.

Belvedere, M, Jalil, N-E, Breda, A, Gattolin, G, Bourget, H, Khaldoune, F, Dyke, G.J., 2013. Vertebrate footprints from the Kem Kem beds (Morocco): a novel ichnological approach to faunal reconstruction. Palaeogeo. Palaeoclim. Palaeoecol. 383, 52-58.

Benkhelil, J., 1989. The origin and evolution of the Cretaceous Benue Trough (Nigeria). J. Afr. Earth Sci. 8, 251-282

Bessedik, M., Mammeri, C., Belkebir, L., Mahboubi, M., Adaci, M., Hebib, H., Bensalah, M., Mansour, B., Mansouri, M.E.H., 2008. Nouvelles données sur 
les ichnites de dinosaurs de la region d'El Bayadh (Crétacé inférieur, Algérie). Palaeovertebrata $36,7-35$.

Brunet, M., Dejax, J., Brillanceau, A., Congleton, J., Downs, W., Duperon-

Laudoueneix, M., Eisenmann, V., Flanagan, K., Flynn, L., Heintz, E., Hell, J., Jacobs, L., Jehenne, Y., Ndjeng, E., Mouchelin, G., Pilbeam, D., 1988. Mise en évidence d'une sédimentation précoce d'âge Barrémien dans le fossé de la Bénoué en Afrique occidentale (Bassin du Mayo Oulo Léré, Cameroun), en relation avec l'ouverture de l'Atlantique sud. C. R. Acad. Sci. Paris, sér. II 306: $1125-1130$.

Choiniere, J.N., Forster, C.A., de Klerk, W.J., 2012. New information on Nqwebasaurus thwazi, a coelurosaurian theropod from the Early Cretaceous Kirkwood Formation in South Africa. J. Afr. Earth Sci. 71-72, 1-17. Congleton, J.D., 1990. Vertebrate paleontology of the Koum Basin, northern Cameroon, and archosauian paleobiogeography in the early Cretaceous.Unpublished Master thesis, Southern Methodist University. 258 pp. Congleton, J.D., Flynn, L.J., Jacobs, L.L., Brunet, M., Dejax, J., Hell, J.V., Pilbeam, D., 1990. Preliminary correlation of continental sediments of the Koum basin, northern Cameroon. Aspects of nonmarine Cretaceous geology. 213-219.

Contessi, M., 2013. A new dinosaur ichnofauna from Tunisia: implications for the palaeobiogeography of peri-Adriatic carbonate platforms in the midCretaceous. Palaeogeo. Palaeoclim. Palaeoecol. 392, 302-311.

Contessi, M., Fanti, F., 2012b. Vertebrate tracksites in the Middle Jurassic-Upper Cretaceous of South Tunisia. Ichnos 19, 211-227.

De Klerk, W.J., Forster, C.A., Sampson, S.D., Chinsamy, A., Ross, C.F., 2000. A new coelurosaurian dinosaur from the early Cretaceous of South Africa. J. Vertebr. Paleontol. 20, 324-332.

Dejax J., Brunet M., 1996. Les flores fossiles du bassin d'Hama-Koussou, Crétacé inférieur du Nord-Cameroun : corrélations biostratigraphiques avec le fossé de la Bénoué, implications paléogéographiques. Bull. Centres Rech. Explor.Prod. Elf-Aquitaine, Mémoire 16, 145-173.

Dejax, J., Michard, J.-G., Brunet, M., Hell, J., 1989. Empreintes de pas de dinosauriens datées du Crétacé inférieur dans le bassin de Babouri-Figuil (Fossé de la Bénoué, Cameroun). N. Jahrb. Geol. Paläontol. Abh. 178, 85-108. 
Demathieu, G.R., Wycisk, P., 1990. Tetrapod trackways from southern Egypt and northern Sudan. J. Afr. Earth Sci. 10, 435-443.

Dumort, J.C., 1968. Carte géologique de reconnaissance et notice explicative sur la feuille Douala-Ouest.

Evans, D.C., Barrett, P.M., Brink, K.S., Carrano, M.T., 2014. Osteology and bone microstructure of new, small theropod dinosaur material from the early Late Cretaceous of Morocco. Gond. Res. 27, 1034-1041.

Eyong, J.T., 2003. Litho-Biostratigraphy of the Mamfe Cretaceous Basin, S.W. Province of Cameroon-West Africa. PhD Thesis. University of Leeds, UK, 265 p.

Eyong, J.T., Wignall, P., Fantong, W.Y., Best, J., Hell, J.V., 2013. Paragenetic sequences of carbonate and sulphide minerals of the Mamfe Basin (Cameroon): indicators of palaeo-fluids, palaeo-oxygen levels and diagenetic zones. J. Afr. Earth Sci. 86, 25-44.

Fairhead, J.D., Okereke, C.S., 1990. Crustal thinning and extension beneath the Benue Trough based on gravity studies, J. Afr. Earth Sci., 11, 329-335

Fanti, F., Cau, A., Hassine, M., Contessi, M., 2013. A new sauropod dinosaur from the Early Cretaceous of Tunisia with extreme avian-like pneumatization. Nature Communications 4, 2080.

Farlow, J.O., 1992. Sauropod tracks and trackmakers: integrating the ichnological and skeletal records. Zubia 10, 89-138.

Flynn, L.J., Brillanceau, A., Brunet, M., Coppens, Y., Dejax, J., DupéronLaudoueneix, M., Ekodeck, G., Flanagan, K.M., Heintz, E., Hell, J., Jacobs, L.L., Pilbeam, D.R., Sen, S., Djallo, S., 1987. Vertebrate fossils from Cameroon, West Africa. J. Vertebr. Paleontol. 7, 469-471.

Genik, G.J., 1992. Regional framework, structural and petroleum aspects of rift basins in Niger, Chad and the Central African Republic (C.A.R.). Tectonophysics, 213, 169-185.

Genik, G.J., 1993. Petroleum geology of the Cretaceous Tertiary rifts basins in Niger, Chad, and Central African Republic: Bull. Am. Assoc. Petrol. Geol. 77, 14051434.

Ginsburg, L., De Lapparent, A.F., Loiret, B., Taquet, P., 1966. Empreintes de pas de vertébrés tétrapodes dans les séries continentales à l'Ouest d'Agadès (République du Niger). C. R. Acad. Sci. Paris, sér. D 263, 28-31. 
Gomani, E.M., 2005. Sauropod dinosaurs from the early Cretaceous of Malawi, Africa. Palaeontologia Electronica 8, 1-37.

Guiraud, R., Bosworth, W., Thierry, J., Delplanque, A., 2005. Phanerozoic geological evolution of Northern and Central Africa: An overview. J. Afr. Earth Sci. 43, 83-143.

Guiraud, R., Maurin, J.C., 1992. Early Cretaceous Rifts of Western and Central Africa. An overview. Tectonophysics 213, 153-168.

Heine, C., Zoethout, J., and Müller, R.D., 2013. Kinematics of the South Atlantic rift. Solid Earth Discuss. 5, 41-116.

Jacobs, L.L., Flanagan, K.M., Brunet, M., Flynn, L.J., Dejax, J., Hell, J.V., 1989.

Dinosaur footprints from the lower Cretaceous of Cameroon, West Africa. pp. 349-351 in Gillette DD, Lockley MG (eds.) Dinosaur tracks and traces. Cambridge University Press

Jacobs, L.L., Winkler, D.A., Downs, W.R., Gomani, E.M., 1993. New material of an Early Cretaceous titanosaurid sauropod dinosaur from Malawi. Palaeontology $36,523-534$.

Lockley, M., 1991. Tracking dinosaurs: a new look at an ancient world, Cambridge University Press, Cambridge, $238 \mathrm{pp}$.

Lockley, M., Farlow, J.O., Meyer, C.A., 1994. Brontopodus and Parabrontopodus ichnogen. nov. and the significance of wide- and narrow-gauge sauropod trackways. Gaia 10, 135-146.

Masrour, M., Pérez-Lorente F., Ferry, S., Içame, N., Grosheny, D., 2013. First dinosaur tracks from the Lower Cretaceous of the Western High Atlas (Morocco). Geogaceta 53, 33-36.

Mannion, P.D., Barrett, P.M., 2013. Additions to the sauropod dinosaur fauna of the Cenomanian (early Late Cretaceous) Kem Kem beds of Morocco: palaeobiogeographical implications of the mid-Cretaceous African sauropod fossil record. Cret. Res. 45, 49-59.

Njoh, O.A., Nforsi, M.B., Datcheu, J.N., 2015. Aptian-Late Cenomanian fluviolacustrine lithofacies and palynomorphs from Mamfe Basin, Southwest Cameroon, West Africa. Int. J. Geosci. 6, 795-811.

Olsen, P.E., Smith, J.B., McDonald, N.G., 1998. Type material of the type species of the classic theropod footprint genera Eubrontes, Anchisauripus, and Grallator 
(Early Jurassic, Hartford and Deerfield basins, Connecticut and Massachusetts, U.S.A.). J. Vertebr. Paleontol. 18, 586-601.

Philip, J., Babinot, J.F., Tronchetti, G., Fourcade, E., Azéma, J., Guiraud, R., Bellion, Y., Ricou, L.E., Vrielynck, B., Boulin, J., Cornée, J.J., Herbin, J.P., 1993 a. Late Cenomanian (94-92 Ma). In: Dercourt, J., Ricou, L.E., Vrielynck, B. (Eds.), Atlas Tethys Palaeoenvironmental Maps, Maps, BEICIP-FRANLAB, Rueil-Malmaison.

Philip, J., Babinot, J.F., Tronchetti, G., Fourcade, E., Guiraud, R., Bellion, Y., Herbin, J.P., Combes, P.J., Cornée, J.J., Dercourt, J., Ricou, L.E., 1993b. Late Cenomanian (94-92 Ma). In: Dercourt, J., Ricou, L.E., Vrielynck, B. (Eds.), Tethys Palaeoenvironmental Maps, Explanatory Notes. Gauthier-Villars, Paris, pp. 153-178.

Popoff, M., 1988. Du Gondwana à l' Atlantique Sud : les connexions du fossé de la Bénoué avec les bassins du Nord-Est brésilien jusqu' à l'ouverture du golfe de Guinée au Crétacé inférieur. J. Afr. Earth Sci. 7, 409-431.

Rauhut, W.M., Werner, C., 1995. First record of the family Dromaeosauridae (Dinosauria: Theropoda) in the Cretaceous of Gondwana (Wadi Milk Formation, northern Sudan). Paläontol. Zeitsch. 69, 475-489.

Richter, U., Mudroch, A., Buckley, L.G., 2013. Isolated theropod teeth from the Kem Kem beds (early Cenomanian) near Taouz, Morocco. Paläontol. Zeitsch. 87, 291-309.

Romano, M., Whyte, M.A., Jackson, S.J., 2007. Trackway ratio: a new look at trackway gauge in the analysis of quadrupedal dinosaur trackways and its implications for ichnotaxonomy. Ichnos 14, 257-270.

Sereno, P.C., Dutheil, D.B., Iarochene, M., Larsson, H.C.E., Lyon, G.H., Magwene, P.M., Sidor, C.A., Varricchio, D.J., Wilson, J.A., 1996. Predatory dinosaurs from the Sahara and Late Cretaceous faunal differentiation. Science 272, 986991.

Sereno, P.C., Beck, A.L., Dutheil, D.B., Larsson, H.C.E., Lyon, G.H., Moussa, B., Sadleir, R.W., Sidor, C.A., Varricchio, D.J., Wilson, G.P., Wilson, J.A., 1999. Cretaceous sauropods from the Sahara and the uneven rate of skeletal evolution among dinosaurs. Science 286, 1342-1347.

Sereno, P.C., Wilson, J.A., Conrad, J.L., 2004. New dinosaurs link southern landmasses in the Mid-Cretaceous. Proc. R. Soc. Lond. B 271, 1325-1330. 
Sereno, P.C., Wilson, J.A., Witmer, L.M., Whitlock, J.A., Maga, A., Ide, O., Rowe, T.A. 2007. Structural extremes in a Cretaceous dinosaur. Plos One 2, e1230.

Sereno, P.C., Brussatte, S.L., 2008. Basal abelisaurid and carcharodontosaurid theropods from the Lower Cretaceous Elrhaz Formation of Niger. Acta Palaeontol. Pol. 53, 15-46.

Taquet, P., 1976. Géologie et paléontologie du gisement de Gadoufaoua (Aptien du Niger). Cahiers de Paléontologie du CNRS.

Thulborn, T., 1989. The gaits of dinosaurs, in: Gilette, D.D. and Lockley, M.G. (eds.), Dinosaur tracks and traces, Cambridge University Press, Cambridge, pp. 3950.

Vullo, R., Courville, P., 2014. Fish remains (Elasmobranchii, Actinopterygii) from the Late Cretaceous of the Benue Trough, Nigeria. Journal of African Earth Sciences 97, 194-206.

Wilson, J.A., Carrano, M.T., 1999. Titanosaurs and the origin of "wide-gauge" trackways: a biomechanical and systematic perspective on sauropod locomotion. Paleobiology 25, 252-267. 
Figure captions

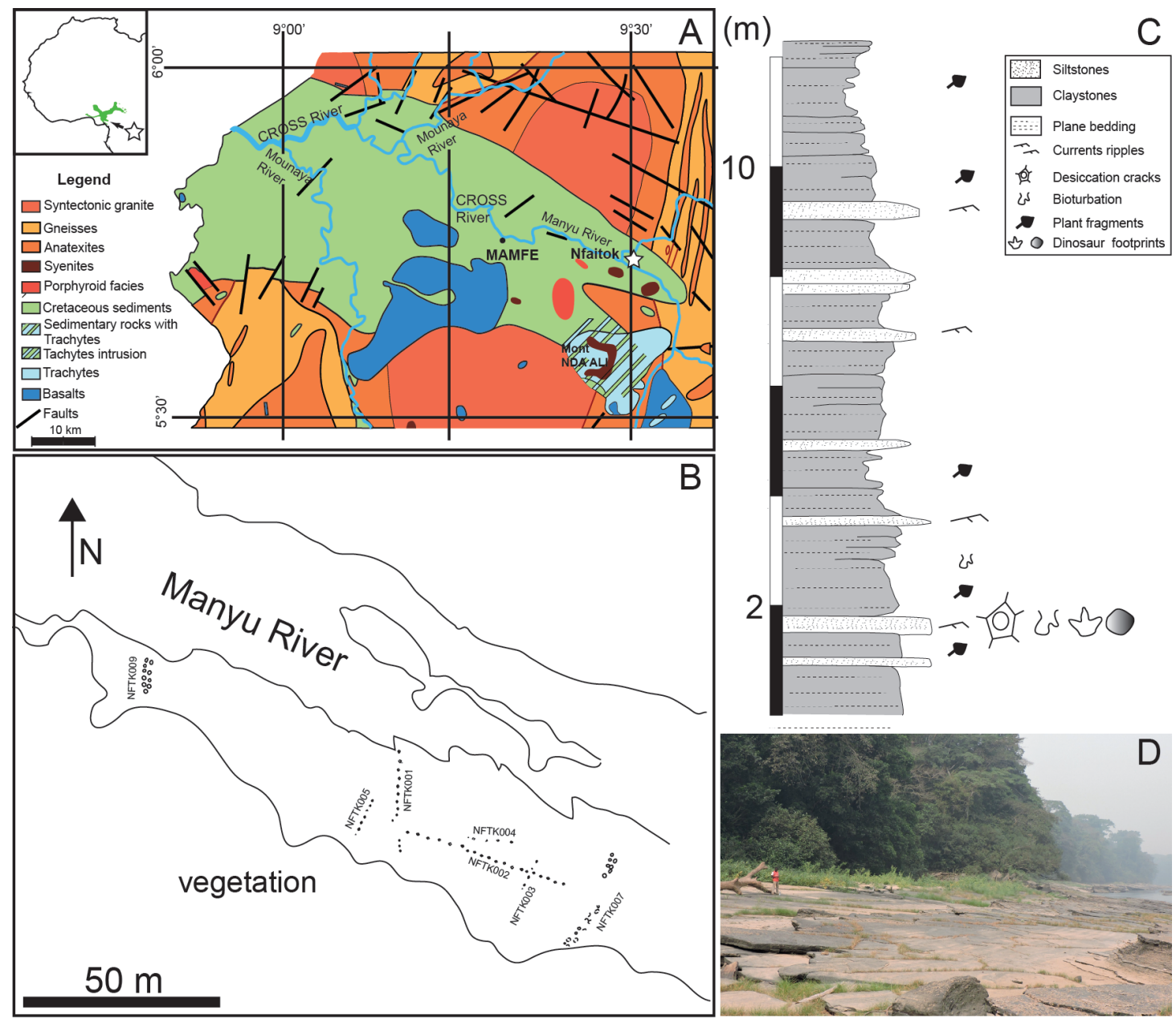

Figure 1. Geological and geographical context of the dinosaur trackways from Nfaitok Bridge, Mamfe Basin, Cameroon. A, Geological map of the Mamfe Basin (extract from geological map of Dumort, 1968) with stars indicating the position of the fossiliferous locality; B, sketch map of the locality showing the distribution of trackways on a single horizon which represents the base of the Manyu member; C, lithological log at Nfaitok Bridge highlighting the bed producing dinosaur trackways; $\mathrm{D}$, general view of the locality looking West. (2 column fitting image; online only color) 


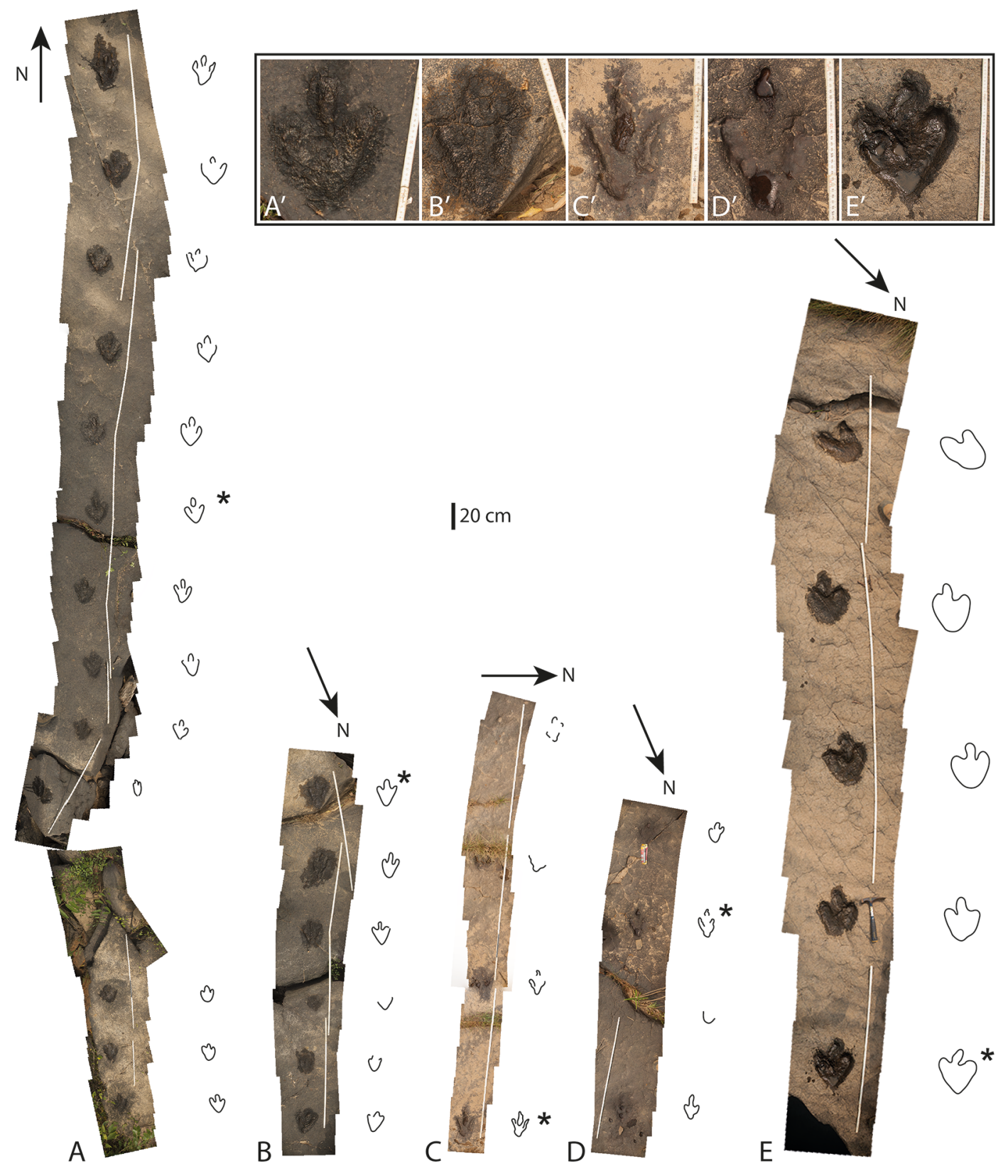

Figure 2. Selection of tridactyl footprints and trackways observed at Nfaitok Bridge, Mamfe Basin, Cameroon. A, NFTK001; B, NFTK005; C, NFTK004; D, NFTK003; E, NFTK006. For each trackway, the best-preserved footprint is indicated by a star and a close-up picture is provided as a subset image in A', B', C', D' and E'. (2 column fitting image; online only color) 


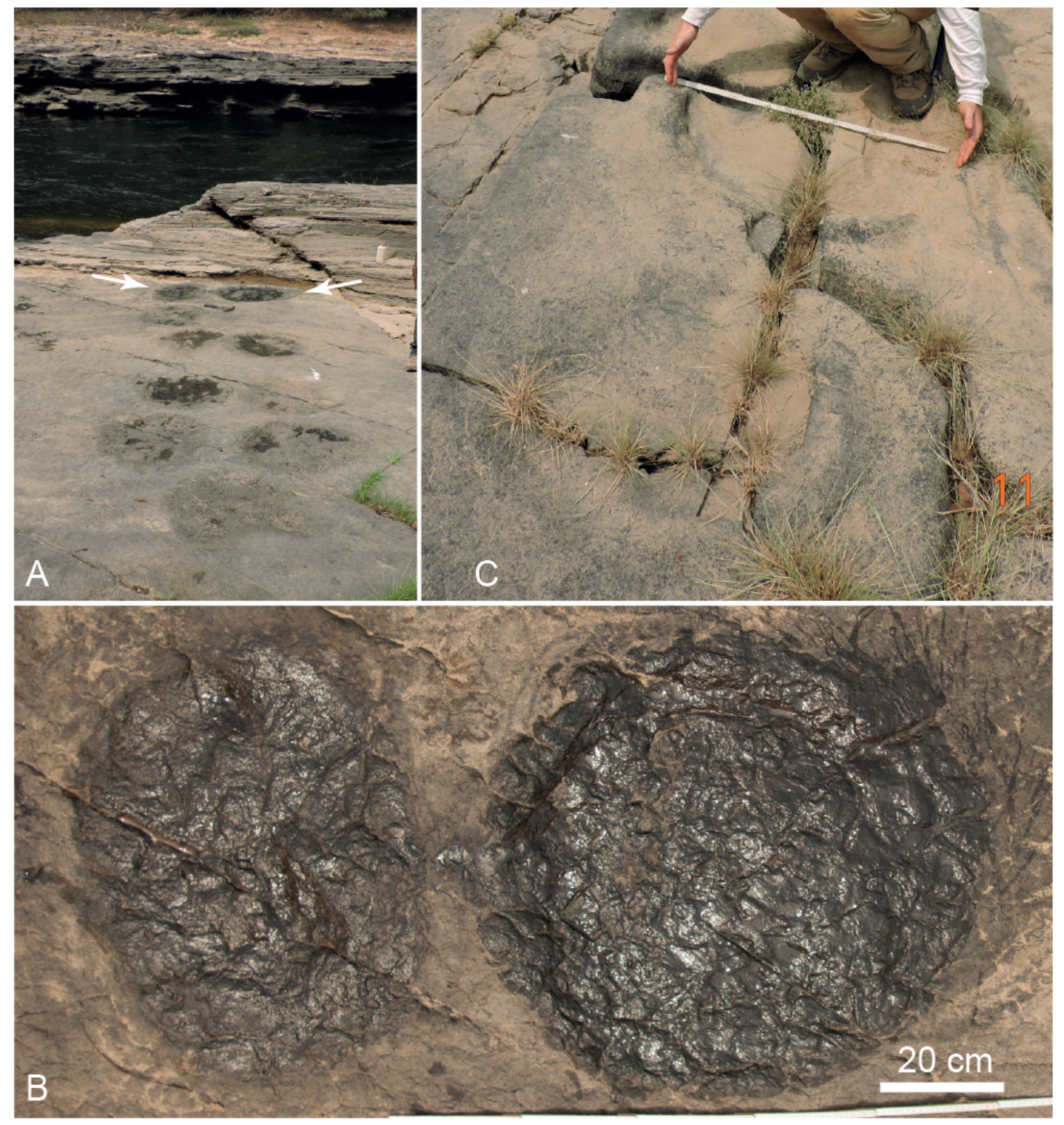

Figure 3. Examples of sauropod footprints observed at Nfaitok Bridge, Mamfe Basin, Cameroon. A, general view of sauropod trackway NFTK009 looking North; B, closeup view of a pes-manus pair in NFTK009 (white arrows in A). C, General view of large circular sauropod pes prints of NFTK010. (1.5 column fitting image; online only color) 


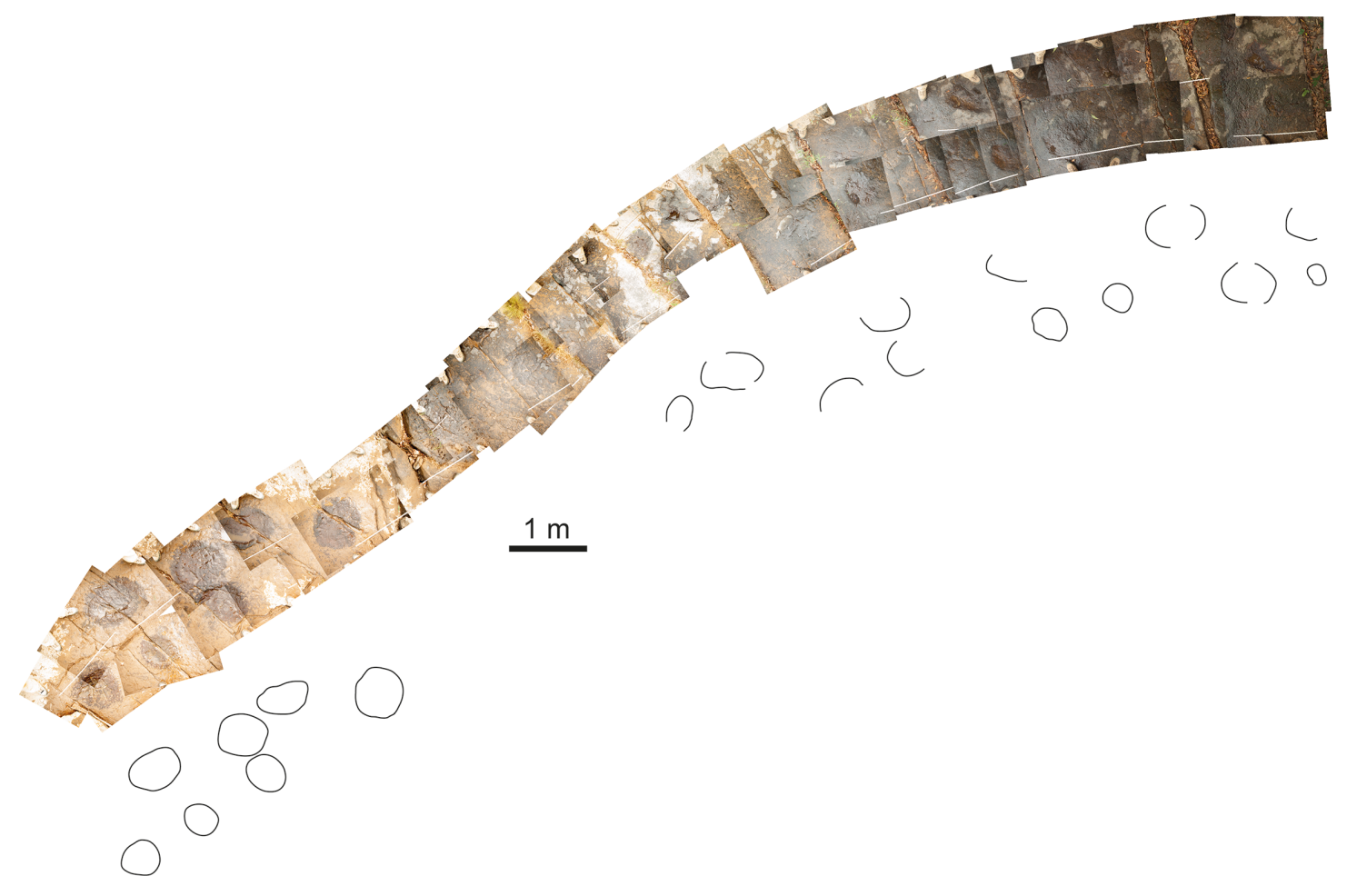

Figure 4. Composite photograph and associated interpretative drawing of sauropod trackway NFTK007 from Nfaitok Bridge, Mamfe Basin, Cameroon. (2 column fitting image; online only color) 
descriptor

tracemaker

direction

observed pes count

observed manus count

mean pes length $(\mathrm{PL})$

mean pes width (PW)

PW/PL ratio

height at hip (Thulborn, 1989)

mean manus length (ML)

mean manus width (MW)

manus outline

mean pes stride length

mean pes pace

trackway width

pes area

manus area

heteropody index (Lockley et al. 1994)

trackway ratio (Romano et al. 2007) from pes

trackway ratio (Romano et al. 2007) from manus

speed (m.s-1) (Alexander, 1976)

speed (km.h-1)

digit II-III angle (in ${ }^{\circ}$ )

digit III-IV angle (in ${ }^{\circ}$ )

interdigital divarication (II-IV)

selected pes for digital angle (* in Fig. 2)

phalangeal pad formula

pace angulation of trackway

divarication angle (in ${ }^{\circ}$, pes print angulation)
NFTK001 NFTK002 NFTK003 NFTK004 NFTK005 NFTK006 NFTK007 NFTK008 NFTK009 NFTK010

theropod theropod theropod theropod theropod theropod sauropod sauropod sauropod sauropod

N $\quad$ ESE $\quad$ SSW W SSW SSW NNE ? NNW ?

$\begin{array}{llllllllll}13 & 20 & 4 & 4 & 6 & 5 & 12 & 2 & 8 & 2\end{array}$

$\begin{array}{lllllllll}- & - & - & - & - & 7 & - & 2\end{array}$

$\begin{array}{llllllllll}21 & 20 & 25 & 25 & 20 & 34 & 54 & ? & 70 & \text { ? } \\ 16 & 13 & 17 & 13 & 17 & 30 & 46 & ? & 75 & 72\end{array}$

$\begin{array}{llllllllll}0.8 & 0.7 & 0.7 & 0.5 & 0.9 & 0.9 & 0.9 & - & 1.1 & -\end{array}$

$\begin{array}{lllllllll}94.5 & 90 & 112 & 112 & 90 & 166 & - & - & -\end{array}$

$\begin{array}{lllllllllll}- & - & - & - & - & & - & & 37 & \text { ? } & 30\end{array}$

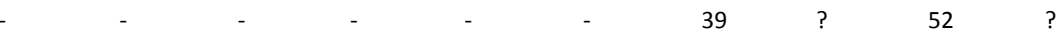

$\begin{array}{lllllll} & - & - & - & - & - & \text { circular ? }\end{array}$

$\begin{array}{llllllllll}148 & 190 & 174 & 230 & 112 & 224 & ? & ?\end{array}$

$\begin{array}{llllllll}71.5 & 110 & 91 & 117 & 60 & 110 & ?\end{array}$

$\begin{array}{lllllll}- & - & - & - & - & - & -\end{array}$

2166

1066

2.03

38.7

32.8

$1.1 ?$

$\begin{array}{lllll}0.9 & 1.4 & 1.0 & 1.5 & 0.6\end{array}$

$\begin{array}{llllll}3.2 & 5.2 & 3.5 & 5.5 & 2.2 & 4.0\end{array}$

$\begin{array}{llllll}26.4 & 21.3 & 22.7 & 21.6 & 20.4 & 20.7\end{array}$

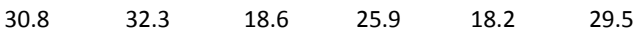

$\begin{array}{llllll}57.2 & 53.6 & 41.3 & 47.5 & 38.6 & 50.2\end{array}$

right left left left left right

not visible not visible 3-3-2 3-?3-2 not visible not visible

$\begin{array}{llllll}158.0 & 176.0 & 171.0 & 171.0 & 171.0 & 168.0\end{array}$

$\begin{array}{lllll}-5.0 & \text { near } 0 & < & -3.4 & -2.0\end{array}$ 